\title{
KEBIASAAN MEROKOK, PENGGUNAAN APD, DAN GANGGUAN PERNAPASAN PEKERJA GUDANG SEMEN TIGA RODA BENGKULU
}

\author{
Sulthanah Utami, Sri Mulyati, NH Noeraini \\ Politeknik Kesehatan Kementerian Kesehatan Bengkulu, Jurusan Keperawatan, \\ Jalan Indragiri Nomor 03 Padang Harapan Bengkulu \\ sultavixx@yahoo.com
}

\begin{abstract}
Respiratory disorders are human lung function damage due to blockage of the respiratory tract by dust respiratory disorders. The research problem is the high smoking and lack of PPE in cement warehouse workers. The purpose of research known relationship of smoking habits and personal protective equipment (PPE) with respiratory distress on three wheels cement warehouse worker Bengkulu. Type a descriptive study using cross sectional approach. Subjects consisted of 35 respondents. Data were collected by questionnaire directly to the job site. Univariate and bivariate analysis with Chi-square test. The results of data analysis showed that the value of $\rho=0.001(\rho<0,005)$ smoking $(81.0 \%)$ there is a link cigarette smoking with breathing disorders, the value $\rho=0.011$ ( $\rho$ $>0,005)$ did not wear PPE $(72 \%)$ there is no relationship APD with respiratory disorders. Suggested workers using PPE in the form of a mask while working or while in the surrounding area cement storage warehouse. The company also advised medical check up on workers to control the physical condition of workers so that the worker is known to have suffered respiratory problems.
\end{abstract}

Keywords : smoking, respiratory problems, APD, cement dust.

\begin{abstract}
Abstrak: Gangguan pernapasan adalah kerusakan fungsi paru manusia akibat tersumbatnya saluran pernapasan oleh debu yang berakibatkan gangguan pada pernapasan. Masalah penelitian adalah tingginya kebiasaan merokok dan kurangnya APD pada pekerja gudang semen. Tujuan penelitian diketahui hubungan kebiasaan merokok dan alat pelindung diri (APD) dengan gangguan pernapasan pada pekerja gudang semen tiga roda Bengkulu. Jenis penelitian deskriptif dengan menggunakan pendekatan cross sectional. Subjek penelitian terdiri dari 35 responden. Pengambilan data dilakukan dengan pengisian kuesioner langsung ke lokasi kerja. Analisis univariat dan bivariat dengan uji Chisquare. Hasil analisis data menunjukkan bahwa nilai $\rho=0,001(\rho<0,005)$ kebiasaan merokok $(81,0 \%)$ dengan OR 15,583 ada hubungan kebiasaan merokok dengan gangguan pernapasan, nilai $\rho=0,011(\rho>0,005)$ tidak memakai APD $(72 \%)$ tidak ada hubungan APD dengan gangguan pernapasan. Disarankan pekerja menggunakan APD berupa masker saat bekerja maupun saat berada di sekitar area gudang penyimpanan semen. Pihak perusahaan juga disarankan melakukan medical check up pada pekerja untuk mengontrol kondisi fisik pekerja sehingga diketahui ada pekerja mengalami gangguan pernapasan.
\end{abstract}

Kata Kunci : kebiasaan merokok, gangguan pernapasan, APD, debu semen.

Kesehatan kerja bertujuan untuk
peningkatan dan pemeliharaan derajat
kesehatan fisik, mental dan sosial yang
setinggi-tingginya bagi pekerja di semua
jenis pekerjaan, pencegahan terhadap
gangguan kesehatan pekerja yang

Kesehatan kerja bertujuan untuk peningkatan dan pemeliharaan derajat kesehatan fisik, mental dan sosial yang setinggi-tingginya bagi pekerja di semua gangguan kesehatan pekerja yang 
kondisi fisiologi dan psikologisnya. Secara ringkas merupakan penyesuaian pekerjaan kepada manusia dan setiap manusia kepada pekerjaan atau jabatannya ( WHO, 2007).

Penyakit paru akibat debu industri mempunyai gejala dan tanda yang mirip dengan penyakit paru yang lain yang tidak disebabkan oleh debu di lingkungan kerja. Penegakan diagnosis perlu dilakukan anamnesa yang teliti meliputi riwayat pekerjaan dan hal-hal lain yang berhubungan dengan pekerja, karena penyakit baru timbul setelah paparan yang cukup lama.

Penyakit akibat kerja yang dimaksud salah satunya adalah kepadatan debu di tempat kerja akibatnya terjadi gangguan pernapasan. Gangguan Pernapasan disebabkan oleh paparan debu yang dapat menyebabkan gangguan pernapasan akut maupun kronis, karena debu adalah salah satu partikel yang melayang di udara, berukuran 1 mikron sampai 500 mikron, umumnya timbul karena aktivitas mekanis seperti aktivitas mesin-mesin industri, bahkan aktivitas manusia lainnya, satu potensi debu dengan ukuran 3-10 mikron akan ditimbun di paru, dan yang berukuran antara 5-10 mikron ini bila terhisap akan tertahan dan tertimbun pada saluran nafas bagian atas dan menyebabkan Infeksi Saluran Pernapasan Atas (ISPA).

Gangguan pernapasan tidak hanya disebabkan oleh konsentrasi debu yang tinggi saja, melainkan juga dipengaruhi oleh karakteristik yang terdapat pada individu pekerja seperti usia, masa kerja pemakaian Alat Pelindung Diri (APD) jenis masker, riwayat merokok dan riwayat penyakit (Hasty, 2011).

\section{BAHAN DAN CARA KERJA}

Penelitian dilakukan di gudang semen Tiga Roda Bengkulu. Jenis penelitian ini adalah observasional analitik dengan pendekatan cross sectional. Populasi penelitian ini adalah seluruh pekerja pada gudang semen Tiga Roda Bengkulu. Penarikan sampel dilakukan dengan teknik total sampling sebanyak 35 orang pekerja dengan melakukan wawancara menggunakan kuesioner untuk mendapatkan informasi mengenai umur, masa kerja, kebiasaan merokok, dan penggunaan APD atau masker.

Hasil analisis dan informasi yang diperoleh dari wawancara diolah dan dianalisis secara deskriptif dengan tabulasi silang untuk memperoleh faktor yang mempengaruhi, dan dijelaskan dalam bentuk tabel dan narasi.

\section{HASIL}

Hasil analisis uji statistik Fisher's Exact Test, kebiasaan merokok dengan gangguan pernapasan pada pekerja gudang semen diperoleh nilai $\rho$ sebesar 0.001 yang berarti bahwa Ho ditolak dan Ha diterima. Penggunaan APD dengan gangguan pernapasan pada pekerja gudang semen diperoleh nilai $p$ sebesar $0.011 \mathrm{Hal}$ ini menunjukkan bahwa ada hubungan antara kebiasaan merokok dengan kejadian gangguan pernapasan pada pekerja gudang semen Tiga Roda Bengkulu (Tabel 1). 
Tabel 1. Kebiasaan Merokok dan Gangguan Pernapasan pada Pekerja Gudang semen Tiga Roda

\begin{tabular}{|c|c|c|c|c|c|c|c|c|c|}
\hline \multirow[t]{3}{*}{ No } & \multirow{3}{*}{$\begin{array}{c}\text { Kebiasaan } \\
\text { Merokok }\end{array}$} & \multicolumn{4}{|c|}{ Gangguan Pernapasan } & \multirow[t]{2}{*}{ Total } & \multirow[t]{2}{*}{$\mathbf{P}$} & \multirow{2}{*}{\multicolumn{2}{|c|}{ OR }} \\
\hline & & \multicolumn{2}{|c|}{$\begin{array}{c}\text { Gangguan } \\
\text { Pernapasan }\end{array}$} & \multicolumn{2}{|c|}{$\begin{array}{l}\text { Tidak Gangguan } \\
\text { Pernapasan }\end{array}$} & & & & \\
\hline & & $\mathbf{N}$ & $\%$ & $\mathbf{N}$ & $\%$ & $\mathbf{N}$ & $\%$ & \multirow{4}{*}{0,001} & 15,583 \\
\hline 1. & Merokok & 17 & $81,0 \%$ & 4 & $19,0 \%$ & 21 & 100 & & \\
\hline \multirow[t]{2}{*}{2.} & Tidak Merokok & 3 & $21,4 \%$ & 11 & $78,6 \%$ & 14 & 100 & & \\
\hline & Total & 20 & $57,1 \%$ & 15 & $42,9 \%$ & 35 & 100 & & \\
\hline
\end{tabular}

Hasil analasis antara kebisasaan merokok dengan gangguan pernapasan pada pekerja gudang semen Tiga Roda Bengkulu menunjukkan dari 35 pekerja yang merokok diperoleh $17(81,0 \%)$ dinyatakan mengalami Gangguan Pernapasan dan $(19,0 \%)$ dinyatakan tidak mengalami Gangguan Pernapasan sedangkan yang tidak merokok mengalami gangguan pernapasan $(21,4 \%)$ dan tidak mengalami gangguan pernapasan $(78,6 \%)$ dengan nilai $p=0,001$, nilai $<0,005$ artinya ada hubungan yang signifikan antara kebiasaan merokok dengan gangguan pernapasan pada pekerja gudang semen Tiga Roda Bengkulu dan nilai OR 15,583 artinya pekerja yang memiliki kebiasaan merokok beresiko 16 kali mengalami gangguan pernapasan dibanding dengan pekerja yang tidak merokok ( Tabel 2).

Tabel 2. Hasil Analisis Variabel APD dan Gangguan Pernapasan pada Pekerja Gudang Semen Tiga Roda Bengkulu

\begin{tabular}{|c|c|c|c|c|c|c|c|c|}
\hline \multirow{3}{*}{ No. } & \multirow{3}{*}{ APD } & \multicolumn{4}{|c|}{ Gangguan Pernapasan } & \multirow{2}{*}{\multicolumn{2}{|c|}{ Total }} & \multirow[b]{2}{*}{$\mathbf{P}$} \\
\hline & & \multicolumn{2}{|c|}{$\begin{array}{c}\text { Gangguan } \\
\text { Pernapasan }\end{array}$} & \multicolumn{2}{|c|}{$\begin{array}{c}\text { Tidak Gangguan } \\
\text { Pernapasan }\end{array}$} & & & \\
\hline & & $\mathbf{N}$ & $\%$ & $\mathbf{N}$ & $\%$ & $\mathbf{N}$ & $\%$ & 0,011 \\
\hline 1. & Tidak Memakai & 17 & $72 \%$ & 6 & $26,1 \%$ & 23 & 100 & \\
\hline 2. & Memakai & 3 & $25,0 \%$ & 9 & $75,0 \%$ & 12 & 100 & \\
\hline & Total & 20 & $57,1 \%$ & 15 & $43 \%$ & 35 & 100 & \\
\hline
\end{tabular}

Hasil tabulasi silang antara kebisasaan merokok dengan gangguan pernapasan pada pekerja gudang semen Tiga Roda Bengkulu menunjukkan dari 35 pekerja yang tidak memakai APD dengan total $17(72 \%)$ mengalami gangguan pernapasan dan $(26,1 \%)$ tidak mengalami gangguan pernapasan sedangkan yang memakai APD $(25,0 \%)$ mengalami gangguan pernapasan dan $(75,0 \%)$ tidak mengalami gangguan pernapasan dengan nilai $\rho=$ 0,011, nilai $>0,005$ (Tabel 2).

\section{PEMBAHASAN}

Hasil penelitian menunjukkan bahwa sebagian besar dari responden $(60 \%)$ yang merokok dan dari penyebaran kuesioner dan wawancara dapat dapat diketahui banyaknya pekerja yang merokok saat bekerja dan tidak memperdulikan kesehatannya dikarenakan responden merasa tidak nyaman jika tidak menghisap rokok dalam sehari, dengan alasan tidak dapat berkonsentrasi saat bekerja. Responden yang tidak merokok dan mengalami gangguan pernapasan $(21,4 \%)$, hal ini karena reponden terlalu banyak menghirup debu saat bekerja dan tidak menggunakan APD. Dengan masa kerja dikategorikan lama $>5$ tahun ada 13 responden dan dikategorikan baru $<5$ tahun ada 22 responden serta umur res-ponden dikategorikan tua 36-56 tahun 
ada 11 responden dan dikategorikan muda 15-35 tahun ada 24 responden.

Hasil penelitian menunjukkan bahwa sebagian besar responden $(65,7 \%)$ tidak memakai APD. Hal ini terjadi karena pekerja merasa tidak nyaman menggunakan APD sehingga dapat mengalami gangguan pernapasan dibanding pekerja yang menggunakan APD. Tidak ada hubungan antara APD dengan gangguan pernapasan karena pekerja memakai APD penutup kepala dari baju usang dan serbet sebagai APD mereka dan yang tidak memakai APD menganggap debu adalah makanan sehari-hari mereka dan tidak memperdulikan kesehatan fisik ditambah lagi kebiasaan merokok sebagai rutilitas mereka. Sedikit terhambat masalah karena peneliti tidak diperbolehkan masuk melihat pekerja melakukan kegiatan saat bekerja oleh pihak perusahaan. Peneliti hanya mendapatkan hasil dari kuesioner dan wawancara oleh pekerja saat jam istirahat.

Hasil penelitian menunjukkan bahwa sebagian besar $(57,1 \%)$ responden mengalami gangguan pernapasan. Gejala yang sering dialami responden yaitu sesak napas, batuk dan bersin terus-menerus serta alergi pada kulit, Hidung dan tenggorokan mereka sering merasa gatal dan merah. Hal ini menunjukkan bahwa diduga mengalami penyakit pneumokoniosis. Dari hasil ini kebiasaan merokok mereka memperkuat adanya gangguan pernapasan dibanding pemakaian APD. Karena kebiasaan merokok mereka dimulai dari rutilitas seharihari baik di area kerja maupun diluar area kerja. Maka perilaku merokok seseorang dapat dikatakan tinggi maupun rendah yang dapat diketahui dari intensitas merokoknya yaitu banyaknya seseorang dalam merokok.

Hasil penelitian menunjukkan dari 14 responden yang tidak merokok dan tidak mengalami gangguan pernapasan sebanyak
(78,6\%), sedangkan sedangkan responden yang tidak merokok dan mengalami gangguan pernapasan $(21,4 \%)$. Dari 21 responden yang merokok dan mengalami gangguan pernapasan $(81,0 \%)$ sedangkan yang merokok dan tidak mengalami gangguan pernapasan hanya 19,0\%).

Hasil penelitian ini menunjukkan bahwa ada responden yang merokok dan mengalami gangguan pernapasan $(81,0 \%)$, hal ini dikarenakan responden merasa tidak nyaman jika tidak menghisap rokok dalam sehari, dengan alasan tidak dapat berkonsentrasi saat bekerja. Sedangkan ada responden yang tidak merokok dan mengalami gangguan pernapasan $(21,4 \%)$, hal ini karena reponden terlalu banyak menghirup debu saat bekerja dan tidak menggunakan APD.

Hasil penelitian ini sejalan dengan Jurnal FKM UNHAS dengan hasil penelitian menunjukkan bahwa pekerja pengangkut semen yang memiliki kebiasaan merokok dan mengalami gangguan fungsi paru sebanyak $21(72.4 \%)$ orang dan yang memiliki fungsi paru normal ada $8(27.6 \%)$ orang, sedang pekerja yang tidak merokok dan mengalami gangguan fungsi paru tidak ada dan yang memiliki fungsi paru normal ada $5(100 \%)$ orang. Hasil analisis menunjukkan bahwa kebiasaan merokok mempengaruhi terjadinya kejadian gangguan fungsi paru.

Hasil penelitian ini sejalan dengan Dorce Mengkidi (2006), dengan hasil penelitian menunjukkan responden yang pernah merokok mengalami gangguan fungsi paru sebanyak 28 orang $(43,82 \%)$ dan tidak mengalami gangguan fungsi paru 36 orang $(56,2 \%)$. Responden yang tidak pernah merokok yang mengalami gangguan fungsi paru sebanyak 19 orang $(70,4 \%)$ dan tidak mengalami 
gangguan fungsi paru $8(29,6 \%)$. dengan Chi Square Test menunjukkan ada hubungan yang bermakna antara kebiasaan merokok dengan gangguan fungsi paru $\left(\mathrm{X}^{2}\right.$ $=4,375 ; \mathrm{p}$ value $=0,036$ )

Hasil penelitian ini sejalan dengan Hasty, 2011, menunjukkan bahwa hasil ratarata KVP pada pekerja yang merokok sebesar $81.69 \%$. Berdasarkan uji statistik yang dilakukan didapatlah nilai $\mathrm{p}$ value sebesar 0.002 yang artinya terdapat hubungan yang signifikan antara kebiasaan merokok dengan KVP.

Perilaku merokok seseorang secara keseluruhan dapat dilihat dari jumlah rokok yang dihisapnya. Seberapa banyak seseorang merokok dapat diketahui melalui intensitasnya, Intensitas adalah besar atau kekuatan untuk suatu tingkah laku. Maka perilaku merokok seseorang dapat dikatakan tinggi maupun rendah yang dapat diketahui dari intensitas merokoknya yaitu banyaknya seseorang dalam merokok.

Kebiasaan merokok Pekerja gudang semen di Tiga Roda Bengkulu termasuk dalam kategori kurang baik dan pemakaian APD yang tidak lengkap sehingga timbul gangguan pernapasan. Dengan masa kerja dikategorikan lama $>5$ tahun ada 13 responden dan dikategorikan baru $<5$ tahun ada 22 responden serta Umur responden dikategorikan tua 36-56 tahun ada 11 responden dan dikategorikan muda 15-35 tahun ada 24 responden.

Hubungan kebiasaan merokok dengan gangguan pernapasan adalah jika pekerja

\section{DAFTAR RUJUKAN}

Dewi. NC, 2010. Pengetahuan tentang Rokok, Pusat Kendali Kesehatan Eksternal dan Perilaku Merokok. Makara, Sosial Humaniora.

Hasty, 2011. Hubungan Lingkungan Tempat Kerja dan Karakteristik Pekerja Dengan KVP pada Pekerja Bagian Plant pada PT. Sibelco Lau- mengurangi kebiasaan merokok saat melakukan aktivitas kerja dan menggunakan APD maka penerapan dalam penggunaan APD akan maksimal yang pada akhirnya pekerja akan terhindar dari resiko gangguan pernapasan.

Pencegahan merupakan tindakan yang paling penting. Regulas dalam pekerjaan dan kontrol pajanan debu telah dilakukan sejak lama terutama di negara industri dan terus dilakukan dengan perbaikan-perbaikan. Pada bentuk pneumokoniosis sub akut dengan manfaat yang didapat untuk efek jangka panjangnya terutama jika bahan penyebab masih ada di paru.

\section{KESIMPULAN}

Berdasarkan penelitian yang dilakukan pada pekerja gudang semen tersebut mengenai kejadian gangguan pernapasan akibat paparan debu semen, maka perlu diupayakan agar para pekerja sebaiknya menggunakan APD berupa masker secara berkelanjutan setiap berada di sekitar area gudang. Selain itu sebaiknya melakukan Medical Check Up kepada pekerja terlebih dahulu sebelum diterima, agar dapat diketahui apakah pekerja memang memiliki penyakit paru atau tidak sebelum bekerja di tempat tersebut dan kemudian melakukan Medical Check Up ulang kepada para pekerja secara berkala setiap tahun.

tan Minerals Jakarta pada Tahun 2011. Universitas Syarif Hidayatullah.

Katherine dkk, 2014. Hubungan Paparan Debu dengan Kapasitas Fungsi Paru Pekerja Penggilingan Padi di Kabupaten Sidrap. 
030 Jurnal Media Kesehatan, Volume 10 Nomor 1, April 2017, hlm. 001-101

Jurnal Kesehatan dan Keselamatan Kerja, FKM Universitas Hasanuddin

Keputusan Menteri Kesehatan Republik Indonesia Nomor 1405/MENKES/SK/XI/2002 tentang Persyaratan Kesehatan Lingkungan Kerja, Perkantoran dan Industri.

Risky dkk, 2012. Faktor yang Mempengaruhi Kejadian Gangguan Fungsi Paru pada Pekerja Pengangkut Semen di Gudang Penyimpanan Semen Pelabuhan Malundung Kota Tarakan, Kalimantan Timur. Jurnal Bagian
Kesehatan dan Keselamatan Kerja FKM UNHAS.

WHO, 2007. Pencegahan dan Pengendalian Infeksi Saluran Pernapasan Akut (ISPA) yang Cenderung Menjadi Epidemi dan Pandemi di Fasilitas PelayananKesehatan.http://www.who.int/csr/resource s/publications/WHO_CDS_EPR_2007_8ba hasa.pdf diakses pada pukul 17.05 WIB 5 maret 2016. 